\title{
Economics
}

2017; 6(2): 24-29

$\mathrm{http}: / /$ www.sciencepublishinggroup.com/j/eco

doi: 10.11648/j.eco.20170602.11

ISSN: 2376-659X (Print); ISSN: 2376-6603 (Online)

\section{Demonstration Effect Theory: A Theoretical Framework of Regulating PPP Reform}

\author{
Fu-guo Cao ${ }^{1}$, De-yun Zhen ${ }^{1}$, Ke Gao ${ }^{1}$, Xiao Feng ${ }^{2}$, Ping Ye ${ }^{3}$ \\ ${ }^{1}$ The School of Finance and Taxation, Central University of Finance and Economics, Beijing, P. R. China \\ ${ }^{2}$ The School of Government, Central University of Finance and Economics, Beijing, P. R. China \\ ${ }^{3}$ The School of Business, Central University of Finance and Economics, Beijing, P. R. China
}

Email address:

zhdynk@126.com (De-yun Zhen),gkfly@126.com (Ke Gao), 348251474@qq.com (Xiao Feng)

\section{To cite this article:}

Fu-guo Cao, De-yun Zhen, Ke Gao, Xiao Feng, Ping Ye. Demonstration Effect Theory: A Theoretical Framework of Regulating PPP Reform. Economics. Vol. 6, No. 2, 2017, pp. 24-29. doi: 10.11648/j.eco.20170602.11

Received: May 6, 2017; Accepted: June 2, 2017; Published: June 6, 2017

\begin{abstract}
PPP (public private partnership) is not only a world trend, but also a Chinese story. Without the guidance of demonstration effect theory, it is hard to interpret the success of PPP in China. However, the lack of research on the demonstration effect theory and the basic logic of explaining the demonstration effect to promote government governance in the background of PPP and supply side reform. This study finds the model promotes the governance of the PPP market mainly through four logical paths, such as solving externalities, government increasing credit, contractual control rights and supplying high-quality information lists. And based on these conclusions, the government should be committed to protecting and supporting enterprises, supplying free high-quality project information, establishing a long-term mechanism to guide the social capital to continuously enter the market.
\end{abstract}

Keywords: Demonstration Effect, Supply Side Reform, Contractual Control Right

\section{Introduction}

In the duration of past 30 years of reform and opening up, government and market have always been the two key factors to determine the overall pattern of China's social and economic development. The disputes-- "More government, or a little more market" come ups and downs. From the logic point of view in historical evolution, the extreme market economy logic lacked predictability and explanatory power, especially when faced with the economic crisis happened in the 1930s. It is difficult to put forward a good remedy for governance crisis, also, easy to trigger the fossilization of resources allocation and social polarization. However, the extreme government intervention logic, may lead the policy dividends and democratic fashion which the reform has brought, and the integration of social habits and the essence of traditional thinking, likely to be hazarded [1].

In the classical economic theory, there are quite adequate discussions about the relationship between government and market. From the Adam Smith era to the beginning of the 20th century, most economists pursued laissez-faire as the best path to achieving sustainable economic growth. The economic crisis happened in the $1930 \mathrm{~s}$, destroyed the cornerstone of classical economic theory and welcomed the Keynesianism of government intervention. However, in the 1970s, in the face of stagflation in economic operation, Keynesianism descended from the altar and neo-liberalism became overwhelmingly popular. Actually, these discussion and disputes focused on the relationship between plan and market. In the late 1980s, the socialist camp experienced the "Eastern European upheaval" and "the disintegration of the Soviet Union", and the relationship between "plan and market" became an overwhelming tendency. The prevailing neo-liberal school advocated that the well-functioning market mechanism should be built on the effective protection of private property rights, in which, the market resources allocation spontaneously occurred, forming the transaction prices, the role of government was only limited to property rights protection, legal system implementation, as well as the maintenance of social order. The consensus of the economists is that the planned economy is not as good as the market economy, and that the improper government intervention will lead to the distortions of the economic operation. The gradual and 
double-track transformation performed in our country will not only lead to dislocation of resources allocation, but also tend to breed corruption and deteriorate income distribution. Hence, this system is much worse than the planned economy [2]. In the domestic environment at that time, the two-track system was a transitional institution arrangement, which was designed to cultivate market pricing outside the planned pricing and gradually replace the planned pricing with market pricing. It is precisely such a seemingly bad and experimental economic policy that has driven China's economy skyrocketing on the road of economic development. Another experimental miracle that the creators made is the PPP (Public private partnership)reform involving in the field of public goods and public services. With the support of the classic market failure theory, the supply market of public goods and public service has been dominated by the government intervention, which seems like a fortress occupied firmly. However, after three years' implementation of the PPP reform practice, the "demonstration project" enormously shook the inherent boundaries of government intervention, and established PPP the leading position in the supply of public goods and public service.

Generally, theories are built to understand the world and transform the world. An indisputable fact is that western classical economic theories mainly reflect, on the basis of western developed countries, the observation of economic phenomenon and economic problems. In the perspective of "two-track system" and "demonstration project", the growth miracle created in China, there is no such a thing as one-size-fits-all development model in Western capitalist countries. Obviously, theories always depend on the prerequisite similarity. However, China's national conditions, resource endowments are widely different from other Western developed countries. Consequently, the prevailing theory in Western developed countries may not be applicable in China; moreover, the western prevailing economic theory seems quite like fashionable clothes, constantly abandoned and replaced by new ones. Also, it can be put that the economic theory may not apply to the Western developed countries [3]. Therefore, when it comes to China's economic growth, something must be take into consideration of the unique context and elements, instead of rigidly adopting the so-called Western mainstream interpretation. Otherwise, it is quite easy to fall into the embarrassing situation- "orange is orange when grown in Huainan, orange is trifoliate orange when grown in Huaibei". Currently, the PPP model is overwhelmingly popular, demonstration projects gain the unexpected achievement, which results in a trend to widely promote the PPP model. This fully demonstrates the theoretical self-confidence, orientation self-confidence and self-confidence of the socialist system of our country. On one hand, the practice of PPP demonstration projects is full of swing; on the other hand, the basic theories of PPP demonstration projects at home and abroad are so scarce that this stage is defined as "uncertain intermediate zone". Accordingly, there is an urgent need for academic attention to make up for the blank concerning relevant theory.

\section{Summarization of Demonstration Theory}

\subsection{The "Demonstration" in the Context of Technological Innovation}

From the context of technological innovation, Baer argues that the core element of the model is the "real environment", that is, the model shows, how the technology works in real environments and how policies affect innovation, which emphasizes that demonstrations should be carried out in the "real environment", rather than performed in "simulation or laboratory environment [4]". Macey and Brown believe that the "full-scaled" model of the core elements, that is, policy and technology involve in the full scale application in the real environment. This definition emphasizes that the promotion of the model is not a small-scaled and tentative development, but a "full-scaled" one [5]. The OTA -- Congressional Technology Assessment Office argues that demonstrations have the following attributes of "inspection, display, market diffusion, innovation, policy development", which also emphasizes that demonstrations should be moved up to the paradigm of national governance. Meanwhile, it focuses that demonstrations embody the functions of promoting technological innovation and market diffusion [6]. The domestic scholars, such as Zhang Hanwei and Guo Yue, presented the definition of a demonstration project based on the domestic context: the demonstration project contains specific technology to run in a real environment in a full scale or very close to a full scale, aiming at promoting innovation and policy-making by demonstrating [7].

On the role of demonstration, Hendry thinks that the demonstration deals with two things: one is the testing for products, technologies, systems, processes and so on; the other one is to promote the commercialization of products or services and market diffusion [8]. From this perspective, the role of demonstrations in technological innovation includes two dimensions--promoting research and development and promoting diffusion. Thus, the scholars' opinions differ greatly and argue whether demonstrations belong to the stage of technical research and development (R \& D) or market diffusion stage. Some scholars believe that the demonstration project belongs to the late stage of $\mathrm{R} \& \mathrm{D}$, the untested stage of the market test. And some scholars believe that the demonstration project is an important part of the market development and belongs to a part of the enterprise marketing plan. Even more, some scholars believe that the demonstration project is a complex ecosystem, belonging to the "uncertainty zone" in the process of innovation. However, there is a more common consensus: demonstration is the special stage in which it connects R \& D and promotion. Based on this argument, innovation can be divided into three stages: $R \& D$, demonstration and promotion. Different stages of technological innovation show different key points and laws. The intermediate stage theory about demonstration, in essence, clarifies the function that demonstration is a kind of technology promotion which is able to cause a market demand. 


\subsection{The "Demonstration" in the Context of Policy Tools}

In the context of a policy tool, the demonstration project possesses two main policy objectives: one is to help policymakers decide whether to implement a policy, and the other one is to promote innovation. The former is called "policy development model", the latter is called "policy implementation demonstration". A common feature of both is to generate information for decision making. The difference is that the former is targeted at federal officials who take the advantage of the information to decide whether to implement a policy. The latter is targeted at the technical staff, who applies the information to determine and judge whether a technology has commercial value. The DOE is divided into experimental and exemplary demonstrations, depending on the policy function of the demonstration project. The purpose of experimental demonstration is to resolve or confirm a judgment; while the primary purpose of the typical demonstration is to persuade.

Public policy implementation requires a certain local field to undertake, and the transformation into a realistic policy objective is not such a connection process as a straight line. It requires local government to make decomposition and secondary planning so as to fulfill the policy objectives. Accordingly, the central level of unity and the local level of diversity will come out, which indicates that public policy has a hierarchical pattern, showing the central and local presentation of principal-agent. The goal of public policy is often difficult to achieve because of the prevalence of information asymmetry and the maintenance of local interests, causing the occurrence of different problems in the process of policy implementation, which seriously violates the authority and integrity of public policy. So how does the demonstration project break the information asymmetry and break the shackles of interest conflict? According to Su Jun, Zhang Hanwei's explanation, demonstration projects not only exist the type of "learning-from-practice", but also "learning-from-application", "Learning-from-interactivity" and even the existence of "learning-from-learning". Different types of learning provide a "platform for knowledge growth" for the demonstration project, and demonstration projects also provide an interactive platform for both government and business stakeholders, on which there are both formal exchange and informal exchanges, both compulsory and non-mandatory exchanges. The interaction between stakeholders, the content, form and effectiveness of the exchange have greatly affected the results of the demonstration project. And based on the judgement that demonstration is driven by technology promotion, putting forward the demonstration can be a good combination of the research and development and the market, which will play a role of "grasp the middle, drive the two ends" [9]. Christopher believes that the demonstration project provides a "toolbox" type of policy tool, which has the accession of certification, publicity display, tax incentives, technical standards, service platform etc. These rich and diverse levels and structures of policy tools can express the government's intentions well and clearly. Generally, government mainly focuses on the demonstration stage, targets the objects clearly, as a result, such problems as vaguer policies, controversy in different government sessions, will be alleviated to certain degree. The theoretical model of the "demonstration mechanism" of public policy implementation suggested by Ye Min and Xiong Wansheng, includes the major elements-- model creator, demonstration implementer, demonstration framework, demonstration point, promotion objectives and demonstration effect. Model framework is the core of the mechanism, which regulates a variety of basic contradictions of the principles and model strategies. The demonstration framework focuses on resolving the contradiction between the point and the surface, providing a linear governance framework, and generally the experience shown is a relatively mature experience that can be seen as a system experience [10].

To sum up, the demonstration is a kind of moderate public policy implementation tool, provides a breakthrough of bureaucratic structures and "block-to-block" models, showing the linear governance framework, but also forming a demand-driven technology promotion, having an effect of " Grasp the middle, drive the two ends ". These conclusions undoubtedly have a high theoretical value, also, to some extent, provide theoretical support for the PPP demonstration project which has achieved great success.

\section{The Way of Demonstration to Regulate PPP and Regulation Path}

The new normal of China's economy means that the economic growth structure has shifted from "demand-deterministic economy" to "supply-deterministic economy", which means that economic growth is no longer mainly driven by the investment, consumption, export troikas decision, but determined by the supply capacity and supply structure [11]. In this sense, the reform of China's supply side is quite necessary to make a long-term preparation, which needs a long period of time to adjust the structural imbalance. Besides, in some fields, annihilation war also needs good preparation, for example, completing the five strategic tasks-"Cutting overcapacity, destocking, deleveraging, reducing costs and identifying growth area [12]". The implementation of the PPP model of public goods and public service in supply market is a long-term layout in supply side reform, also a protracted war, in which the problem to be solved is how to provide better service. This also led us to have a deep consideration of the basic theory of demonstration projects. In order to cope with the declining macroeconomic situation, structural overcapacity and the deficiency of effective supply, and to make economic development step out of the "old normal" shackles, the state launched the remedy for "supply-side reform" to govern the economy. From the perspective of state governance, PPP is still the redefinition of government and market boundaries. It is through the mechanism innovation that the efficiency of supplying public goods and public service can speed up; social welfare can be 
improved, which naturally possesses the attributes of "supply side". The demonstration role of demonstration projects is an important starting point for the effective implementation of the PPP reform; its original intention is to pursue the best practice of PPP, to conduct the supply side governance in public goods and public service market. From this logic point of view, the demonstration project is the starting point, and the supply side is the driving force; both have the inherent logic of consistency.

\subsection{Demonstration Is Low-Cost, High-Quality Information on Public Goods, Regulating the Direction of Resource Allocation}

Analysis of the starting point of economic development is the endowment of resources, that is, the supply of resources. The resource supply capacity of an economy is given at any given time, and the given supply capacity determines that the resource is always in a scarce state. Under the rigid constraints of resource deficiency, the resource allocation follows the configuration logic that maximizes private interests. PPP projects generally have an enormous initial investment, a long operating cycle, many supporting links, but also involve in a certain technical threshold and experience accumulation. The constraints of these factors dictate that social capital with the ability to gain access to the PPP field is scarce. At the same time, the Ministry of Finance PPP project library has nearly 10,000 projects, accumulated more than 10 trillion of investment, and is searching for the right social capital. It is from both sides of supply and demand that the scarcity of social capital resources is verified.

How to break the "private interests to maximize" the resources allocation logic? Guide the scarcity of social capital to achieve optimal allocation. These problems can be solved precisely by the "model" government that "concentrates on doing things". The evaluation of the demonstration project has a strict evaluation criteria and procedures, collecting a large number of experts and professors in theoretical circles and practice. The results of the review essentially provide the catalog information of the high quality PPP project, where the government is the supplier of the quality project information. With the high-quality demonstration project information base, the choice of social capital for the project has more targeted, can use the lowest search cost to obtain more valuable project information, the project implementation is successful, and the probability of the expected benefits are greater. Thus it can be seen that in the PPP context, "demonstration" provides low-cost, high-quality information public goods, providing guidance to the market allocation of resources.

\subsection{Demonstration Is a Governance Paradigm that Governs the Boundaries of Government and Markets}

From the construction to the operation of the PPP projects, it shall be subject to the approval or filing involving in different departments of development and reform, territory, revenue, finance etc. It can be described as "too many bosses", even having the phenomenon of "Yamen fight (Yamen means government office in feudal China)". At this point, the opponents of government and enterprises are not at the same rank in the game, and enterprises are often at a disadvantage in the game. The traditional logic to solve such problems is either to achieve private harmony through the "political black gold" or to stick in the indefinite delay. This is a serious institutional ills produced in the "bureaucratic" governance structure and block governance model. At the same time, PPP projects may face serious negative externalities, such as the loss of land acquisition to the interests of farmers, the emissions of "strange" flavor from open-air sewage treatment plant. These negative externalities in traditional governance models are difficult to provide systematic solutions.

"Demonstration", as a new governance framework, expresses the government's concern for a particular area, or project. It provides a "central - project" type of linear governance paradigm; this governance paradigm is also the constraints to the power boundaries of the bureaucratic management structure, intangibly overcoming the "coordination" problem that exists in enterprises. At the same time, under the new governance framework, the government and social capital also have the power to jointly promote innovation, and jointly overcome the negative problems caused by PPP project construction. Thus, as a linear paradigm of governance, "demonstration" provides a standard system of supply and co-governance pattern.

\subsection{Demonstration Is a Credit Mechanism that Regulates the Balance Between Private Interests and Government Credit}

The founder of the theory of mechanism design, Havitz put forward the concept of "incentive compatibility": under the market mechanism, for limited rational economic people, the logical starting point of decision-making is the maximization of personal interests. If there is a system arrangement that can make the goal of maximizing personal interests consistent with the goal of maximizing public value, such an institutional arrangement is called "incentive compatibility". Public goods, public services are designed to meet public needs. The government has the responsibility to supply at a lower cost. Hence, the PPP project's yield is generally low (as opposed to competitive commercial projects), which is inconsistent with the investment logic of maximization of personal interests and capital profitability. However, PPP, as a long-term mechanism of government and social capital cooperation, embedded cash flow stability, minor income risk and other natural advantages. Some projects even have policy monopoly and exclusiveness; therefore, it has a certain investable feature. But many local governments are under the burden of debts, government chiefs' change frequently, instead, what the social capital is most worried about is the government's credit. Government, as an agent of public demand, is easier to achieve the high public value if having a high credit index; on the contrary, it is difficult to attract the attention of social capital if having a low credit index. This requires an "incentive compatible" mechanism to balance the contradictions existed in capital profitability and government credit. 
How to design such an "incentive compatible" mechanism? The key is to create a good business environment, to enhance the security and credibility of social capital. At this time government credit-adding is a good path choice. The so-called government credit-adding refers that government shall depend on its credit, apply the organizational and political advantages which state and government at all levels possess, through the system, mechanism construction and system supply, shall remedy the market failure caused by insufficient system, so as to guide and standardize market behavior, to improve the judgment expectation of market as the main body, to achieve "government and business" win-win. The function of the PPP demonstration project, in addition to confirming that a project is a replicable and popular implementation example, also disseminates the positive evaluation of the project by the central government. This evaluation is a transmission of government credit, often known as "Red top" label. The label urges the local government to take an organizational advantage, and give a certain privilege to the demonstration project in the following aspects -- project approval, capital injection, bank loans, project acceptance, tax incentives and other resources. Through the resource mobilization in all aspects, government and social capital form a collaborative development pattern, so that the demonstration effect of demonstration projects is enlarged by the means of geometric amplification. It can be inferred that the demonstration is an effective credit-adding mechanism.

\subsection{Demonstration Is a Kind of Contract Management, Regulates the Reform Path of the PPP Supply Side}

PPP embeds itself with such advanced concepts and charming elements as the value for money, competition, life cycle cost management, contract management, gestating major change factors. In the process of cooperation, government and social capital are a special partnership. The mutual rights, obligations, risk sharing and distribution of benefits need to be agreed to the contract. The definition of government rights and obligations is a typical "agreed control". The so-called "agreed control" is the rights and obligations of the government that can be written in advance, and the residual control is the right of the enterprise that cannot be written in advance.

The "agreed control" in PPP mode is the public value that government represents; the "residual control" is the private interests that social capital is in pursuit of. In this case, public value and private value alternately coexists, and the erosion of public value is likely to be the means of gaining private value. The degree of realization of public value depends on how the "agreed control" is agreed, not on the public's desire. As the government is not entirely rational government, moral hazard may also exist in enterprises, the insufficient agreement is likely to be a normal. So there is a need for a standardized contract representing the public value. The "demonstration" mechanism essentially provides a standardized public value supply contract from the supply side [13]. This is an example of a border that can be copied and can be promoted. Under the standard boundary demarcation, the role of the government is the collaborators and supervisors, which are limited, representing the public's ability, to exercise supervision over the performance of public services and public goods and pay for performance. Corporate responsibility is to promote innovation, improve the quality of public services and public goods supply and supply efficiency. At the same time, the "supply path" of the "demonstration" is very clear, and the joint efforts of the government and social capital are realized through the standard of "agreed control" and "residual control" to realize market governance in the supply side of the public goods and public services [14].

\section{Policy Enlightenment}

\subsection{Reflections on the Relationship Between Government and Enterprises}

\subsubsection{The Government Should Target the Protector and the Supporter of the Enterprise}

If the relationship between government representing the public interest and the society representing the private interest is regarded as a transactional relationship, then the contract is a function of the terms of the transaction. Whether it is a long-term contract, or a short-term one, it is in line with the logic of the market economy. The PPP project regulates the "agreed control" in the form of a contract, which is, protecting the degree of realization of the public value, but also protecting and supporting the private value of the enterprise. Both sides of government and enterprises are in accordance with the contract to advocate their own rights and fulfill their obligations, which is typical market logic. It is also a respect for value orientation of "private value maximization". At this time, although the government plays the role of protector and supporter for enterprises, in the natural market logic, it achieves the public value and meets the public needs.

\subsubsection{The Government Should Target Suppliers of High Quality Information}

The advantages of enterprises lie in efficiency, and the advantages of governments lie in organization. Government can take advantage of the administrative resources in its hands, play an organizational advantage, cluster industry elites and experts together, supply high-quality information through specific procedures. An important reason for the success of the PPP demonstration project is that government has set up a platform for obtaining free high-quality project information, on which companies can get access to high-quality information at a low cost, and information asymmetry is no longer an obstacle for business selection. And the supply of a large amount of free high-quality project information relies solely on the ability of one enterprise, which is difficult to achieve; and the enterprise has no driving-force to do it either, because it violates the nature of business profitability. From the perspective of the basic theory of finance, free high-quality project information is a public product without competitive and there is no exclusiveness, which is the obligation of government supply. 


\subsection{Reflections on Industrial Policy}

\subsubsection{The Government's Industrial Policy Should be Targeted at Key Support}

Demonstration provides a "central-project" governance framework, but the governance framework is targeted, not all projects are concerned by the central government, the scope is only limited to demonstration projects. Is it possible to incorporate all the projects into the "central - project" governance framework? The answer is an obvious no. Because resources are always scarce, this scarcity includes social capital, as well as the government's service delivery capacity. In the rigid constraints of resources, the position of industrial policy should be focused on support, rather than a comprehensive package covering every aspect; otherwise, it is easy to cause trade-offs, and consequently it is difficult to achieve the desired results while conducting industrial policy.

\subsubsection{Government's Industrial Policy Should Focus on Building Long - Term Mechanism}

Credit-adding is the transmission of government credit, and the essence of credit-adding is the concept of "market platform". That is to say, the band between government and enterprises is inseparable. Both government and enterprises are the concrete participants in market activities. Government is not aiming at grabbing the rent, instead, at guiding private sectors to be qualified market participants. As a credit-adding mechanism, the PPP Demonstration Project greatly mobilizes the enthusiasm of private sectors. As explained by Chen Yuan that the bottleneck of infrastructure construction, apparently, it is the lack of funds, but essentially, it is the lack of continuous entering regulation.

\section{Conclusion}

Through the research on PPP model and supply-side context, it is found that demonstration is a low-cost, high-quality information public product, demonstration is a kind of governance paradigm, demonstration is a kind of credit mechanism, and demonstration is a kind of contract management. It contributes to achieve the supply side governance in public goods and public service. These findings will enlighten our consideration about the boundaries of government and business and the position of government policies.

\section{References}

[1] Jingdong qu. project: a new state governance system [J] Social Sciences In China, 2012 (5): 113-130.

[2] Murphy, Kevin M, Andrei Shleifer, and Robert W Vishny industrialization and big push [J]. journal of political Economics, 1989 (97): 1003-1026.

[3] Yifu lin. New Structural Economics [M]. Beijing. Peking University Press, 2012, 2-12.

[4] Walter S. Bear. Analysis of federally funded demonstration projects: executive summary [R]. America: Rand company, 1976.

[5] Susan M. Macey, Marilyn A. Brown. Demonstration as a policy Instrument with Energy Technology example [J]. Science communication, 1990 (11), 219-236.

[6] T. K. GLENNAN, Jr., W.F.HEDERMAN, jr., L. L. JOHNSON, R. A. RETTIG. The role of demonstrations in federal R\&D policy [R]. America: Rand company, 1976.

[7] Hanwei Zhang Yue Guo. Research on the Influence Mechanism of Government Demonstration Project on Technological Innovation [J]. Technology and Law, 2014 (6): 1055-1073.

[8] Chris Hendry, Paul Harborne, James Brown. So what do innovating Companies Really Get from public funded demonstration projects and trials? Innovation lessons from solar photovoltaic sand wind [J]. Energy policy, 2010 (38): 4507-4519.

[9] Jun su Hanwei Zhang. "Demonstration" in the context of technological innovation: stages.

[10] Projects and tools [J]. Chinese Soft Science, 2014 (12): 60-66. Min Ye Wansheng Xiong. "Demonstration": a central mechanism for the implementation of Chinese policy [J]. Journal of Public Administration, 2013 (4): 15-25.

[11] Gang Gong. On the Reform of Supply Side under the New Normal [J]. Journal of Nankai University (Philosophy and Social Sciences), 2016 (2): 17-22.

[12] Angang Hu Shaojie Zhou. Supply side structural reform [J]. Journal of Tsinghua University (Philosophy and Social Sciences), 2016 (2): 17-22.

[13] Jianjiang Song. Government credit growth, loan efficiency and economic growth [J]. Financial Development Review, 2016 (3): 130-13.

[14] JunSheng Li Dongmin Dong. On the Nature of Internet Search Service and Its Market Supply [J]. Manage World, 2016 (8): $1-15$. 